\title{
First report of a begomovirus and associated betasatellite in Rosa indica and in India
}

\author{
Anurag Kumar Sahu • Avinash Marwal • M. S. Shahid • \\ Chitra Nehra • R. K. Gaur
}

Received: 1 May 2014 / Accepted: 5 September 2014 /Published online: 16 September 2014

(C) Australasian Plant Pathology Society Inc. 2014

\begin{abstract}
The complete genome sequences of a begomovirus and associated betasatellite was obtained by the rolling circle amplification from rose (Rosa indica) exhibiting dwarfing, leaf distortion and leaf curling symptoms from Rajasthan, India. The sequence of the begomovirus was determined to be 2,741 bp and showed the typical genome arrangement of an monopartite Old World begomovirus. The sequence showed the highest nucleotide sequence identity $(98 \%)$ to an isolate of Rose leaf curl virus (RoLCuV), confirming it as an isolate of RoLCuV. The sequence of the rose begomovirus associated betasatellite (1,349 bp) displayed greater than $97 \%$ nucleotide sequence identity to Digera leaf curl betasatellite. Our analysis also demonstrated that recombination events shaped the evolutionary history of RoLCuV. To our knowledge, this is the first report of $\mathrm{RoLCuV}$ associated with betasatellite infecting rose in India.
\end{abstract}

Keywords Geminivirus · Begomovirus $\cdot$ Betasatellite · Rosa indica

Anurag Kumar Sahu and Avinash Marwal are equal contribution

A. K. Sahu • A. Marwal $\cdot$ C. Nehra $・$ R. K. Gaur $(\bowtie)$

Department of Science, Faculty of Arts, Science and Commerce,

Mody University of Science and Technology, Lakshmangarh,

Sikar 332311, Rajasthan, India

e-mail: gaurrajarshi@hotmail.com

A. K. Sahu

e-mail: anuragsahhu@gmail.com

A. Marwal

e-mail: marwal_avinash@yahoo.co.in

C. Nehra

e-mail: chitra.nnehra@gmail.com

M. S. Shahid

Department of Biosciences, COMSATS Institute of Information

Technology, Sahiwal 57000, Pakistan

e-mail: shafiqinayat@gmail.com
Geminiviruses are an emerging group of plant viruses infecting most of the economically important crops and ornamental plants throughout the world (Nawaz-ul-Rehman et al. 2009). Based on the genome organization, sequence phylogeny, host range and the vector, the geminiviruses are classified into seven genera: Becurtovirus, Eragrovirus, Turncurtovirus, Topocuvirus, Curtovirus, Mastrevirus and Begomovirus (Brown et al. 2012). The majority of members of this family belong to the genus Begomovirus and viruses of this genus are transmitted by the whitefly (Bemisia tabaci) (Briddon et al. 2001). The viruses of this genus are further divided into two sub-groups, bipartite begomoviruses (with genomes consisting of two components known as DNA-A and DNAB) and monopartite begomoviruses (with genomes consisting of a single component homologous to the DNA-A component of the bipartite viruses). The discovery of betasatellite (ssDNA satellites previously known as DNA $\beta$ ) associated with monopartite members of the genus have increased in the last decades worldwide (Briddon et al. 2008). Betasatellites are half the size of their helper viruses (approximately 1,350 nucleotides in length) with a highly conserved structure gene encoded in the complementary-sense known as $\beta \mathrm{C} 1$. The satellite region also contains a hairpin-loop structure TAA/ GTATTAC similar to the origin of replication of geminiviruses, and an Adenine rich region (A-rich) (Briddon et al. 2003).

Geminiviruses are an emerging group of plant-infecting viruses in the tropical and subtropical region of the world. Their emergence is thought to be caused by many factors including, but not limited to, the high insect vector populations, the existence of alternative hosts and response to changes in their environment (such as alterations in cropping systems and/or population dynamics of insect vectors). Previously, diverse begomoviruses isolated from different geographical locations were reported to have the capacity to interact with betasatellites (Briddon et al. 2003; Saunders et al. 


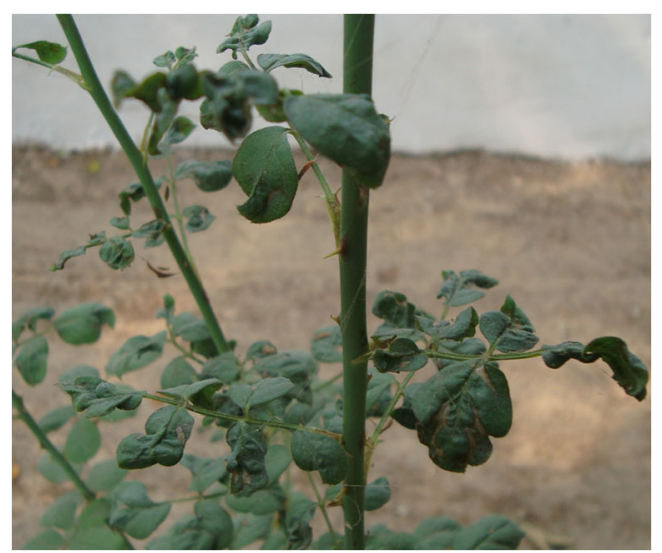

Fig. 1 Symptoms of RoLCuV on rose (R. indica)

2008). Recently, Marwal et al. (2012) have reported a high rate of recombination and pseudo-recombination events that contribute in the evolution of new viral species in begomoviruses from ornamental plants in India.

Rose ( $R$. indica) is a woody perennial plant that is cultivated mostly in gardens throughout India. In a survey for begomoviruses, leaves of twenty rose plants exhibiting dwarfing, leaf distortion and leaf curling typical of begomovirus symptoms with 50 to $80 \%$ disease incidence were collected from 10 gardens around the Shekhawati region of Rajasthan, India in 2012 (Fig. 1). Total DNA was extracted from the collected symptomatic and two apparently healthy leaves by using a kit (viral DNA from serum/plants,
Chromous Biotech Pvt. Ltd., India) as per the manufacturer's instructions. Extracted DNA was used as a template for the rolling circle amplification (RCA) (Haible et al. 2006), yielding high molecular weight concatemers (data not shown). Digestion of RCA with PstI, Bam HI, XhoI and EcoRI resulted in $\sim 2.7$ and $\sim 1.3 \mathrm{~kb}$ fragments, respectively from infected plants but not from healthy plants. The restriction fragments of RCA products were cloned into pBluescript SK + vector (Stratagene, La Jolla, USA). All the clones obtained in each case showed the same restriction pattern and therefore only one clone for each RCA restriction product (pRLV10 for begomovirus and $\mathrm{pRLV} \beta$ for betasatellite) was selected and sequenced completely (Xcelris Genomics, Ahmedabad, India). The attempts to detect alphasatellite and/or DNA-B either by PCR (by using universal primers for both alphasatellite and DNA-B components) or RCA were unsuccessful (Rojas et al. 1993; Briddon et al. 2002).

The complete nucleotide sequence of the begomovirus (pRLV10) isolated from rose was determined to be 2,741 bp (GenBank acc. KF584008). Analysis of the sequence of pRLV10 showed the virus to be a typical Old World begomovirus with two ORFs (V1-V2) in the virion-sense and four ORFs (C1-C4) in the complementary-sense and a predicted stem loop structure which is the origin of replication of the virion-sense strand (Rojas et al. 2005). The sequence comparison showed pRLV10 to be highly identical to Rose leaf curl virus (RoLCuV; GQ478342) reported from Pakistan in rose (Khatri et al. 2014) (97\% nucleotide sequence (a)

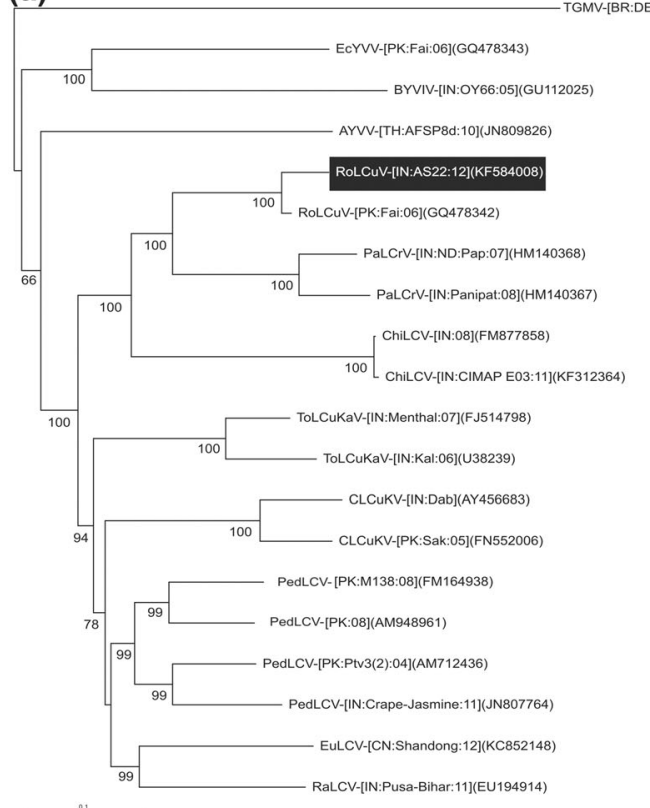

Fig. 2 Phylogenetic dendrograms based on alignments of selected begomovirus (a) and betasatellite (b) sequences. Begomovirus sequences used for comparison are mentioned in the respective trees. Vertical branches are arbitrary, horizontal branches are proportional to calculated

(b)

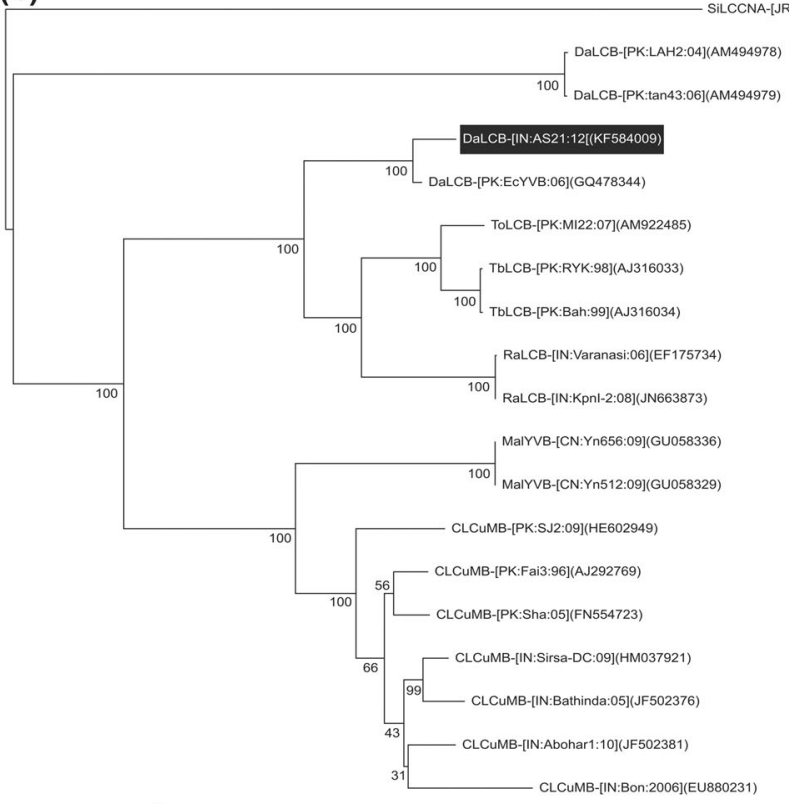

mutation distances. Values at nodes indicate percentage bootstrap values (1,000 replicates). The isolates that were collected as part of this study are highlighted 
Table 1 Whitefly transmission and host range study of RoLCuV

*PCR was done by using universal coat protein (AC 1048 and AV 494; Marwal et al. 2012) and betasatellites primer (beta01 and beta02; Briddon et al. 2002)

\begin{tabular}{llll}
\hline Test plant & Common name & Symptoms & PCR result* \\
\hline Raphanus sativus & Radish & Leaf curling, yellowing & + \\
Solanum lycopersicum & Tomato & Leaf curling, yellow mosaic & + \\
Carica papaya & Papaya & Leaf curling, leaf stunting & + \\
Capsicum annuuam & Chili & Leaf curling & + \\
Abelmoschus esculentus & Bhendi & Leaf curling & + \\
Rosa indica & Rose & Leaf curling & + \\
Gossypium arboreum & Cotton & Yellow mosaic stunting & + \\
& Health Control & - & - \\
\hline
\end{tabular}

identity). Further analysis confirmed that ORFs of the pRLCV10 displayed greater than $98 \%$ nucleotide sequence identity with RoLCuV (GQ478342) confirming its identity as an isolate of RoLCuV. In the phylogenetic tree based on the genome monopartite, begomovirus pRLV10 grouped with RoLCuV (Fig. 2a). Based on the presently applicable species demarcation threshold of $89 \%$ for begomoviruses (Fauquet et al. 2008), we conclude that the virus isolated from $R$. indica is an isolate of $\mathrm{RoLCuV}$ for which we propose the isolate descriptor RoLCuV-Sikar.

The complete nucleotide sequence of the associated betasatellite ( $\mathrm{pRLV} \beta$ ) was also determined to be $1,349 \mathrm{bp}$ (GenBank acc. KF584009). The sequence of $p R L V \beta$ shows the typical arrangement of earlier betasatellites, with a single ORF in the complementary sense $(\beta C 1$; coordinates $513-$ 187 ), a region rich in adenine residues (coordinates 7191013), and a sequence motif highly conserved between all betasatellites, known as the satellite conserved region (SCR; coordinates 1265-14). The complete genome of $p R L V \beta$ shown here has the highest levels of sequence identity (97.4\%) to a Digera leaf curl betasatellite (DaLCB; GQ478344). The predicted sequence of the $\beta C 1$ of $p R L V \beta$ displays the highest levels of amino acid sequence identity $(97 \%)$ to the $\beta C 1$ of DaLCB. In phylogenetic analysis it grouped with DaLCB to be most closely related to an isolate identified in Faisalabad, Punjab, Pakistan, which is situated close to the border with India (Fig. 2b). These findings indicate that the betasatellite characterised here is an isolate of DaLCB for which the isolate descriptor DaLCB-Sikar is proposed. Previously, isolates of DaLCB have been identified in a Digera arvensis plant with yellow vein symptoms infected with Cotton leaf curl Rajasthan virus [FM202328] and in rose plant with Rose leaf curl virus [GQ478342].

To determine the transmission and host range of the begomovirus infection, the viruliferous whiteflies were inoculated on healthy rose and other plants as described in Table 1. Non-viruliferous whiteflies were allowed an acquisition access period (AAP) of $24 \mathrm{~h}$ on a symptomatic rose plant. The whiteflies were then transferred to the uninfected test plant and remained there for the $24 \mathrm{~h}$ inoculation access. The whiteflies were then eliminated by treating plants with imidacloprid and symptoms on inoculated plants were monitored after 28 days (dpi). The experiments were conducted in the insect-proof cage maintained at $27-30{ }^{\circ} \mathrm{C}$. The presence of virus in symptomatic plants was further confirmed through PCR by using universal coat protein (AC 1048 and AV 494; Wyatt and Brown 1996) and betasatellites primer (beta01 and beta02; Briddon et al. 2002) (Data not shown). Our results showed that the virus was transmitted by whiteflies in a persistent manner and caused systemic leaf curling and stunting on host plants (Table 1).

Recombination analysis for both pRLV10 and pRLV $\beta$ was also done by RDP (Martin and Rybicki 2000). The analysis for pRLV10 shows that there are three recombination fragments (coordinates 216-1448, 1777-1796 and 2188-2589). The recombination in the first fragments was detected in VI, $\mathrm{C} 2$ and $\mathrm{C} 3$ regions with major parent Eclipta yellow vein virus (GQ478343) and minor parent Pedilanthus leaf curl virus (AM712436). The second recombination fragment (C1 region) showed the major parent Radish leaf curl virus (EF175733) and minor parent Tomato leaf curl Pakistan virus (FM164938) while the third recombination fragment (C4 region) showed major parent Ageratum yellow vein virus (JN809821) and minor parent Euphorbia leaf curl virus (KC852148) (Table 2). Similarly RDP analysis of betasatellite showed the five recombination fragments (Table 2).

Leaf curl disease of rose is a relatively recent phenomenon. This is the first time RoLCuV and associated betasatellite have

Table. 2 Recombination analysis of DNA-A and betasatellite of RoLCuV by using Recombination detection program (RDP)

Recombination fragment Major parents Minor parents $p$-value and Coordinates

\begin{tabular}{llll}
\hline DNA-A (KF584008) & & & \\
216-1448 & GQ478343 & AM712436 & $8.283 \times 10^{-18}$ \\
2188-2589 & JN809821 & KC852148 & $4.408 \times 10^{-03}$ \\
Betasatellites(KF584009) & & & \\
$990-1243$ & EF175734 & DQ020491 & $9.670 \times 10^{-02}$ \\
\hline
\end{tabular}


been identified in India. RoLCuV has so far only been identified from $R$. chinensis (Chinese rose) in Faisalabad, Pakistan (Khatri et al. 2014). Further studies to determine the diversity of this virus and associated betasatellite from this country are needed.

Acknowledgments The authors are thankful to Department of Biotechnology, New Delhi, India (BT/PR13129/GBD/27/197/2009 for financial assistance during the present study.

\section{References}

Briddon RW, Mansoor S, Bedford ID, Pinner MS, Saunders K, Stanley J, Zafar Y, Malik KA, Markham PG (2001) Identification of DNA components required for induction of cotton leaf curl disease. Virology 285:234-243

Briddon RW, Bull SE, Mansoor S, Amin I, Markham PG (2002) Universal primers for the PCR-mediated amplification of DNA $\beta$; a satellite associated with some monopartite begomoviruses. Mol Biotechnol 20:315-318

Briddon RW, Bull SE, Amin I, Idris AM, Mansoor S, Bedford ID, Dhawan P, Rishi N, Siwatch SS, Abdel-Salam AM, Brown JK, Zafar Y, Markham PG (2003) Diversity of DNA $\beta$, a satellite molecule associated with some monopartite begomoviruses. Virology 312:106-121

Briddon RW, Brown JK, Moriones E, Stanley J, Zerbini M, Zhou X, Fauquet CM (2008) Recommendations for the classification and nomenclature of the DNA- $\beta$ satellites of begomoviruses. Arch Virol 153:763-781

Brown JK, Fauquet CM, Briddon RW, Zerbini M, Moriones E, NavasCastillo J, King AMQ, Adams MJ, Carstens EB, Lefkowitz EJ (2012) Virus taxonomy - ninth report of the international committee on taxonomy of viruses. Associated Press, Elsevier Inc, London, pp 351-373

Fauquet CM, Briddon RW, Brown JK, Moriones E, Stanley J, Zerbini M, Zhou X (2008) Geminivirus strain demarcation and nomenclature. Arch Virol 153:783-821

Haible D, Kober S, Jeske H (2006) Rolling circle amplification revolutionizes diagnosis and genomics of geminiviruses. J Virol Methods 135:9-16

Khatri S, Nahid N, Fauquet C, Mubin M, Nawaz-ul-Rehman MS (2014) A betasatellite-dependent begomovirus infects ornamental rose: characterization of begomovirus infecting rose in Pakistan. Virus Genes. doi:10:1007/SII262-014-1076-6

Martin D, Rybicki E (2000) RDP: detection of recombination amongst aligned sequences. Bioinformatics 16:562-563

Marwal A, Prajapat R, Sahu A, Gaur RK (2012) Computational characterization of Begomovirus infecting two ornamental plants: Jasminum sambac and Millingtonia hortensis. Asian J Biol Sci 5: 240-249

Nawaz-ul-Rehman MS, Mansoor S, Briddon RW, Fauquet CM (2009) Maintenance of an old world betasatellite by a new world helper begomovirus and possible rapid adaptation of the betasatellite. $\mathrm{J}$ Virol 83:9347-9355

Rojas MR, Gilbertson RL, Russel DR, Maswell DP (1993) Use of degenerate primers in the polymerase chain reaction to detect whitefly-transmitted geminiviruses. Plant Dis 77:340-347

Rojas MR, Hagen C, Lucas WJ, Gilbertson RL (2005) Exploiting chinks in the plant's armor: evolution and emergence of geminiviruses. Annu Rev Phytopathol 43:361-394

Saunders K, Briddon RW, Stanley J (2008) Replication promiscuity of DNA $\beta$ satellites associated with monopartite begomoviruses: deletion mutagenesis of the Ageratum yellow vein virus DNA $\beta$ satellite localises sequences involved in replication. J Gen Virol 89:31653172

Wyatt SD, Brown JK (1996) Detection of subgroup III geminivirus isolates in leaf extracts by degenerate primers and polymerase chain reaction. Phytopathology 86:1288-1293 